KONDISI KAWASAN RAWAN BENCANA TSUNAMI \title{
DI KECAMATAN MUNCAR \\ KONDISI KAWASAN RAWAN BENCANA TSUNAMI
}

Moch, Shofwan'), Yoga Pratama2)

${ }^{122)}$ Program Studi Perencanaan Wilayah dan Kota, Universitas PGRI Adi Buana Surabaya

email: $\underline{\text { hofwan.moch@gmail.com }}$

\begin{abstract}
Abstrak
Kecamatan Muncar merupakan kawasan pesisir yang masuk dalam zona inti pengembangan kawasan minapolitan dan memiliki jumlah penduduk terbesar kedua di Kabupaten Banyuwangi, serta merupakan kawasan rawan bencana tsunami. Tujuan penelitian ini untuk mengidentifikasi karakterisitik penggunaan lahan dan menganilisis tingkat risiko zona kawasan rawan bencana tsunami serta menganalisis pengaruh kawasan rawan bencana tsunami terhadap penggunaan lahan di Kecamatan Muncar. Metode pengumpulan data menggunakan observasi lapangan dan studi literatur serta menggunakan metode analisis deskriptif kuantitatif dengan teknik persentase dan overlay union.
\end{abstract}

Kata Kunci: Penggunaan lahan, Tsunami, Zona rawan tsunami

\begin{abstract}
Muncar District is a coastal area that is included in the core zone of the development of the minapolitan area and has the second largest population in Banyuwangi Regency, and is a tsunami hazard area. The purpose of this study was to identify the characteristics of land use and to analyze the level of risk of tsunami-prone zones and to analyze the influence of tsunami-prone areas on land use in Muncar District. Data collection methods used field observations and literature studies and used quantitative descriptive analysis methods with percentage and overlay union.
\end{abstract}

Keywords: Land use, Tsunami, Tsunami risk zone

\section{PENDAhULUAN}

Peraturan Daerah Kabupaten Banyuwangi No. 08 Tahun 2012 Tentang Rencana Tata Ruang Wilayah Kabupaten Banyuwangi Tahun 2012 - 2032 menyebutkan bahwa Kecamatan Muncar masuk ke dalam zona inti pengembangan kawasan minapolitan. Kecamatan Muncar juga masuk ke dalam kawasan rawan bencana tsunami dengan klasifikasi Kawasan Rawan Bencana Zona I (Sangat rawan) dengan luas $1.141 \mathrm{Ha}$, Zona II (Rawan) dengan luas $1.083 \mathrm{Ha}$, dan Zona III (Agak rawan) seluas $2.027 \mathrm{Ha}$. Penggunaan lahan dan kegiatan perekonomian serta jumlah penduduk juga menjadi perhatian dalam kawasan rawan bencana, Kecamatan Muncar menjadi pengembangan kawasan minapolitan serta menjadi kawasan rawan bencana gelombang pasang dan tsunami dalam pengembangan kawasan minapolitan pada Kecamatan Muncar tentunya akan berimbas pada penggunaan lahan, kegiatan perekonomian, dan perkembangan kependudukan. Permasalahan tentang bencana merupakan permasalahan yang tergolong prioritas, hal itu disebabkan oleh banyaknya frekuensi kejadian bencana serta luasnya wilayah yang menjadi prioritas penanganan (Shofwan, 2018).

Kecamatan Muncar terletak di sebelah selatan Kota Banyuwangi dengan luas $8.773,30 \mathrm{Ha}\left(87,73 \mathrm{~km}^{2}\right)$ pada ketinggian $10-$ 50 mdpl (meter di atas permukaan laut). Kecamatan Muncar memiliki 10 desa. Berdasarkan posisi geografisnya, Kecamatan 
Muncar memiliki batas-batas administrasi yang disajikan sebagai berikut:

$\begin{array}{ll}\text { Utara } & \text { : Rogojampi, Srono } \\ \text { Timur } & \text { : Selat Bali } \\ \text { Selatan } & \text { : Tegaldlimo } \\ \text { Barat } & \text { : Srono, Cluring }\end{array}$

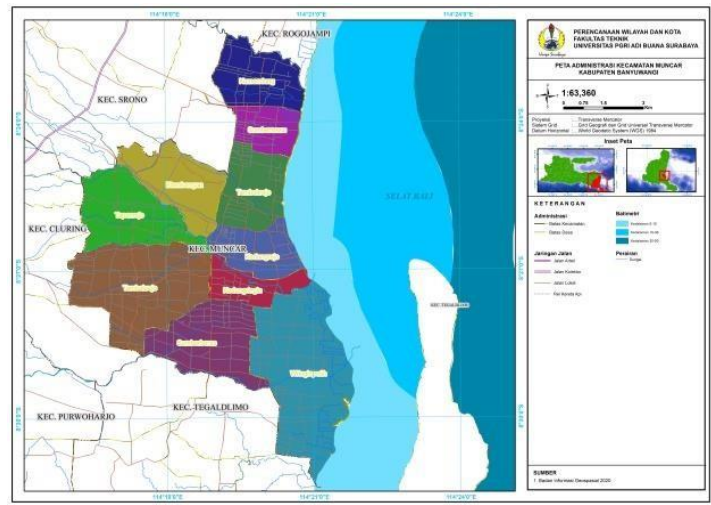

Gambar 1 Peta Administrasi Kecamatan Muncar

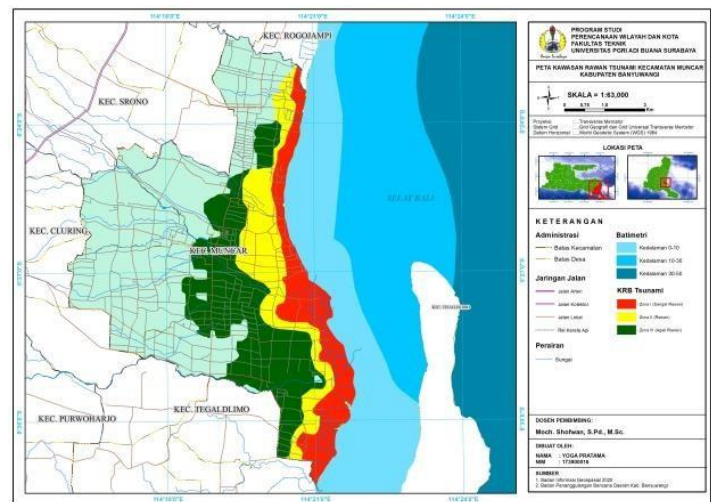

Gambar 2 Peta Kawasan Rawan Bencana Tsunami Kecamatan Muncar

\section{KAJIAN LITERATUR DAN PEGEMBANGAN HIPOTESIS}

Penelitian Faiz Islam, Sawitri Subiyanto, L.M. Sabri dengan judul "Penentuan Risiko dan Kerentanan Tsunami di Kebumen dengan Citra Alos" dengan hasil literaturnya berupa peta lokasi kerentanan dan risiko bencana tsunami.

\section{METODE PENELITIAN}

3.1 Pengumpulan Data

Metodologi pengumpulan data merupakan salah satu prosedur untuk mendapatkan kondisi riil pada data yang ditinjau dari berbagai sumber data, yaitu:

1) Sumber Data Primer

Survei primer merupakan kegiatan pengumpulan data yang dilakukan secara langsung dan memiliki tujuan untuk memperkuat keadaan sebenarnya pada lokasi penelitian (Sugiyono, 2011). Survei primer dilakukan dengan cara dokumentasi, dokumentasi adalah mengumpulkan data dengan cara mengambil data-data dari catatan, dokumentasi dan administrasi yang sesuai dengan masalah yang diteliti. Dalam penelitian ini dokumentasi diperoleh melalui dokumendokumen gambaran atau foto kondisi penggunaan lahan di lapangan dan hasilnya dispasialkan dalam bentuk peta, foto, atau gambar. Hasil dari observasi ini dapat berupa data kualitatif dan kuantitatif.

2) Sumber Data Sekunder

Survei sekunder adalah kegiatan pengumpulan data secara tidak langsung melalui media perantara. Data sekunder pada umumnya adalah bukti, catatan atau laporan historis yang tersusun dalam arsip yang telah dipublikasikan maupun tidak dipublikasikan. Pengumpulan data sekunder dilakukan dengan cara pengambilan data melalui instansi pemerintahan maupun instansi swasta yang berkaitan dengan penelitian ini. Data ini sangat dibutuhkan guna memperkuat data-data yang belum tersedia pada publikasi masyarakat. Pengambilan data dari instansi, seperti BAPPEDA (Badan Penanggulangan Bencana Daerah) dan Badan Pusat Statistik, Kantor Kecamatan Muncar, Kabupaten Banyuwangi yang mendukung cakupan wilayah dan unit analisis dalam penelitian.

\subsection{Teknik Analisis Data}

1) Analisis karakteritik penggunaan lahan digunakan untuk mengetahui penggunaan lahan pada Kecamatan Muncar. Metode analisis yang digunakan adalah deskriptif kuantitatif dengan melakukan presentase pada setiap jenis penggunaan lahan pada masing-masing kawasan rawan bencana rendah, sedang dan tinggi dari seluruh penggunaan lahan di Kecamatan Muncar.

2) Analisis tingkat kerawanan bencana tsunami menggunakan metode analisis mix methods kuantitatif dan kualitatif 
dengan teknik analisis skoring tingkat kerawanan bencana dan teknik analisis overlay union dengan klasifikasi indeks ancaman, indeks kerentanan, dan indeks kapasitas dikutip dari Peraturan Kepala Badan Nasional Penanggulangan Bencana Tentang Pedoman Umun Pengkajian Risiko Bencana dalam penilaian tingkat kerawanan bencana tanah tsunami.

\section{HASIL DAN PEMBAHASAN}

\subsection{Hasil}

Kondisi penggunaan lahan Kecamatan Muncar pada jenis penggunaan lahan terbangun dan tidak terbangun dapat dilihat pada Tabel 1.

Tabel 1 Klasifikasi Penggunaan Lahan

\begin{tabular}{|c|l|c|c|}
\hline No. & Desa & $\begin{array}{c}\text { Lahan } \\
\text { Terbangun } \\
(\mathrm{Ha})\end{array}$ & $\begin{array}{c}\text { Lahan } \\
\text { Tidak } \\
\text { Terbangun } \\
(\mathrm{Ha})\end{array}$ \\
\hline 1 & Blambangan & 152.12 & 621.09 \\
\hline 2 & Kedungrejo & 341.86 & 215.03 \\
\hline 3 & Kedungringin & 152.33 & 240.36 \\
\hline 4 & Kumendung & 155.58 & 514.67 \\
\hline 5 & Sumberberas & 319.05 & 620.22 \\
\hline 6 & Sumbersewu & 109.93 & 275.88 \\
\hline 7 & Tambakrejo & 253.79 & 1234.36 \\
\hline 8 & Tapanrejo & 222.76 & 678.76 \\
\hline 9 & Tembokrejo & 328.56 & 334.38 \\
\hline 10 & Wringinputih & 267.20 & 1725.37 \\
\hline
\end{tabular}

Desa Kedungrejo, Desa Tembokrejo, dan Desa Sumberberas memiliki kawasan dengan penggunaan lahan terbangun yang tinggi, Desa Kedungrejo dan Desa Tembokrejo yang masuk dalam kategori tingkat risiko zona tinggi.

\subsection{Pembahasan}

Analisis karakteristik penggunaan lahan terletak di Kecamatan Muncar, dengan menggunakan teknik analisis persentase penggunaan lahan Kecamatan Muncar dari citra satelit Google Earth tahun 2021 kemudian diolah di ArcGis yang menghasilkan penggunaan lahan Kecamatan Muncar.

Analisis Tingkat Risiko Zona Kawasan Bencana Tsunami dalam penentuan tingkat risiko zona kawasan bencana tsunami memerlukan dua indeks yaitu indeks ancaman dan indeks kerentanan. Indeks kerentanan mempunyai 4 faktor yaitu kerentanan sosial, kerentanan ekonomi, kerentanan fisik dan kerentanan ekologi.

1) Berdasarkan hasil analisis kondisi karakterisik penggunaan lahan Kecamatan Muncar dengan menggunakan digitasi dan survey lapangan, terdapat 10 jenis penggunaan lahan, di antaranya perkebunan, permukiman, pertanian, tambak, mangrove, perairan, industri, perkantoran, perdagangan dan jasa, ruang terbuka hijau (RTH) dan sarana transportasi berupa pelabuhan. Penggunaan lahan yang terletak di Kecamatan Muncar didominasi oleh lahan pertanian dengan persentase $54,61 \%$ dan yang paling rendah adalah hutan mangrove dengan persentase $0,01 \%$.

2) Berdasarkan hasil analisis diketahui bahwa tingkat risiko zona kawasan rawan bencana tsunami Kecamatan Muncar terdiri dari tiga kategori yaitu rendah $4433.79 \mathrm{Ha}$, sedang $1552.10 \mathrm{Ha}$ dan tinggi 2787.40 Ha. Desa Wringinputih,

Desa Kedungringin, Desa Kedungrejo dan Desa Tembokrejo masuk dalam kategori tingkat risiko zona kawasan bencana tinggi dikarenakan wilayah desa tersebut juga merupakan kawasan rawan bencana tsunami dengan kategori KRB I atau kawasan yang memiliki tingkat rawan bencana tsunami tinggi berdasarkan indeks ancaman. 


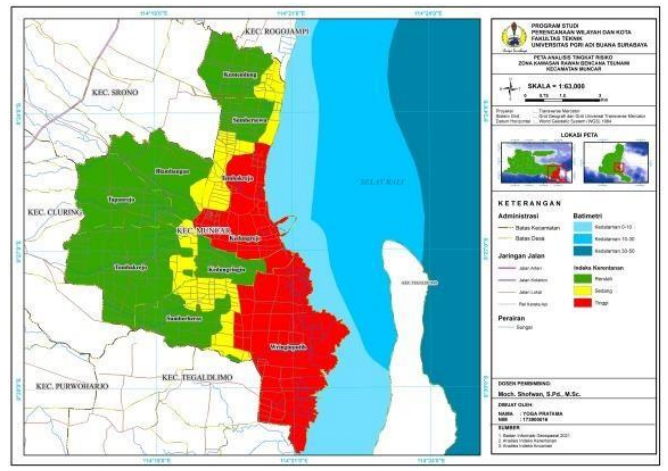

Gambar 3 Peta Tingkat Risiko Zona Kawasan Rawan Bencana Tsunami Kecamatan Muncar

\section{KESIMPULAN}

Hasil identifikasi karakteristik penggunaan lahan Kecamatan Muncar dengan menggunakan teknik analisis persentase yaitu penggunaan lahan yang terbagi menjadi 10 jenis antara lain perkebunan dengan persentase $11,26 \%$, permukiman $24 \%$, pertanian $54,61 \%$, tambak $6,62 \%$, mangrove, $0.57 \%$, perairan $0.89 \%$, industri $0.47 \%$, perkantoran, perdagangan dan jasa $0.06 \%$, ruang terbuka hijau $0.08 \%$ dan transportasi $0.85 \%$. Penggunaan lahan pertanian dengan persentase tinggi yaitu 54\% disebabkan pada wilayah desa yang jauh dari pesisir sehingga memiliki wilayah yang dominan pada lahan pertanian, penggunaan lahan terbangun seperti permukiman, industri, dan perdagangan dan jasa mengelompok pada daerah dekat pesisir.

Hasil identifikasi tingkat risiko zona kawasan rawan bencana tsunami Kecamatan Muncar dengan menggunakan teknik analisis skoring dan analisis spasial overlay union. Terdapat tiga risiko zona kawasan rawan bencana tsunami di Kecamatan Muncar yaitu tingkat risiko rendah, risiko sedang, dan risiko tinggi. Diketahui bahwa tingkat risiko zona kawasan rawan bencana tsunami Kecamatan Muncar terdiri dari 3 kategori yaitu rendah $4433.79 \mathrm{Ha}$, sedang $1552.10 \mathrm{Ha}$, dan tinggi 2787.40 Ha. Desa Wringinputih, Desa Kedungringin, Desa Kedungrejo, dan Desa Tembokrejo masuk dalam kategori tingkat risiko zona kawasan bencana tinggi dikarenakan wilayah desa tersebut juga merupakan kawasan rawan bencana tsunami dengan kategori KRB I atau kawasan yang memiliki tingkat rawan bencana tsunami tinggi berdasarkan indeks ancaman.

Desa Kedungrejo, Desa Tembokrejo, dan Desa Sumberberas memiliki kawasan dengan penggunaan lahan terbangun yang tinggi, Desa Kedungrejo dan Desa Tembokrejo yang masuk dalam kategori tingkat risiko zona tinggi, sehingga pada wilayah desa dengan penggunaan lahan terbangun yang besar juga masuk dalam kategori tingkat risiko tinggi bencana tsunami.

\section{UCAPAN TERIMAKASIH}

Penelitian ini telah mendapat dukungan dari Program Studi Perencanaan Wilayah dan Kota, Fakultas Teknik, Universitas PGRI Adi Buana Surabaya.

\section{REFERENSI}

Arridha, R. Y. (2019). Sistem Informasi Geografi Analisis Overlay. In Sistem Informasi Geografi. Diambil dari https://www.academia.edu/38586597/Siste m Informasi Geografis SIG Overlay An alysis_Analisis_Overlay.com

Ahyuni. (2016). Perencanaan Penggunaan Lahan. Jakarta: CV. Kecana.

Arsyad, S. (2010). Konservasi Tanah dan Air. Bogor: IPB Press.

Hernisa, A. (2012). Evaluasi Kemampuan Lahan Terhadap Penggunaan Lahan/ Penutup Lahan dan RTRW. Tugas Akhir. Bogor. Fakultas Pertanian, IPB.

Ilyas. (2006). Manajemen Risiko Tsunami Untuk Penataan Ruang di Pesisir Perkotaan Pacitan Jawa Timur. Volume 2 No. 2, 22 Juni 2013.

Peraturan Kepala Badan Nasional Penanggulangan Bencana Nomor 02 Tahun 2012 Tentang Pedoman Umum Pengkajian Risiko Bencana. Jakarta.

Peraturan Menteri Pekerjaan Umum No.22/PRT/M/2007 Tentang Pedoman Penataan Ruang Kawasan Rawan Bencana Longsor.

Pusat Vulkanologi dan Mitigasi Bencana Geologi Diambil dari http://vsi.esdm.go.id/gallery/picture.php?/ 270/category/19 
Sadyohutomo, M. (2012). Tata Guna dan Penggunaan Lahan. Surabaya: Fakultas Teknik Sipil dan Perencanaan Universitas PGRI Adi Buana.

Shofwan, M. (2018) Mitigasi Bencana Erosi dan Longsor (Kajian Teori dan Teknis). Sidoarjo: Mejatamu.
Shofwan, M. (2021). Post Disaster Needs Assessment (PDNA). Sidoarjo: Meja Tamu.

Sugiyono. (2007). Metode Penelitian Kuantitatif, Kualitatif dan Research Development. Bandung: Alfabeta.

Undang-undang Nomor 24 Tahun 2007 Tentang Penanggulangan Bencana. Jakarta. 